that antigens present only in secretors $\left(\mathrm{Le}^{\mathrm{b}}\right)$ or in higher quantities in secretors $(\mathrm{H}$ type $\mathrm{l}$ in addition to $\mathrm{H}$ type 2$)^{23}$ might act as one of the receptors for some viruses is under investigation.

This work is supported by grants from the Scottish Cot Death Trust, TENOVUS-Scotland, and the North East Scotland Meningitis Appeal. We thank Dr R H Fraser and Dr G Inglis from the Glasgow and West of Scotland Blood Transfusion Service for helpful discussions and for the monoclonal antibodies used in this study, Dr D A J Tyrell and Mrs C Brown of the MRC Common Cold Unit for supplying specimens of nasal washings, Dr R A Elton for statistical advice, and Mrs M K Cole for preparing the manuscript. MWR has a grant from the Overseas Research Student Awards Scheme.

1 Haverkorn MJ, Goslings WRO. Streptococci, ABO blood groups and secretor status. Am f Hum Genet 1969;21:360-75

2 Chaudhuri A, Das Adhikary CR. Possible role of blood-group secretory substances in the aetiology of cholera. Trans $R$ Soc Trop Med Hyg 1978;72:664-5.

3 Kinane DF, Blackwell CC, Brettle RP, Weir DM, Winstanley FP, Elton RA. $\mathrm{ABO}$ blood group, secretor state, and susceptibility to recurrent urinary ABO blood group, secretor state,

4 Blackwell CC, Jónsdótir $K$, Hanson M, Todd WTA, Chaudhuri AKR, Mathew B, et al. Non-secretion of ABO blood group antigens predisposing Mathew $\mathrm{B}$, et al. Non-secretion of $\mathrm{ABO}$ blood group antigens predisposing
to infection by Neisseria meningitidis and Streptococcus pneumoniae. to infection by $\mathrm{Ne}$.

5 Blackwell CC, Jónsdóttir K, Hanson MF, Weir DM. Non-secretion of ABO antigens predisposing to infection by Haemophilus influenzae. Lancet 1986;ii:687.

6 Blackwell CC, May SJ, Brettle RP, MacCallum CJ, Weir DM. Secretor state and immunoglobulin levels among women with recurrent urinary tract infections. F Clin Lab Immunol 1987;22:133-7.

7 Thom SM, Blackwell CC, MacCallum CJ, Weir DM, Kinane DF, Wray D. Non-secretion of $\mathrm{ABO}$ blood group antigens and susceptibility to infection by Candida species. FE.MS Microbiol Immunol 1989;7:401-6.
8 Andersen J, Laurizen E. Blood groups and diabetes mellitus, Diabees 1960;9:20-4

Blackwell CC, James VS, Weir DM, (iemmell JD, Patrick AW, Collier A et al. Secretor status of patients with insulin dependent or non-insulin dependent diabetes mellitus. BMF 1987;295:1024-5.

10 Collier A, Patrick AW, Toft AD, Blackwell CC, James VS, Weir DM Increased prevalence of non-secretors in patients with Graves' disease: evidence for an infective aetiology. $B M 7$ 1988;296:1162.

11 Shinebaum R, Blackwell CC, Forster PJG, Hurst NP, Weir DM, Nuki G. Non-secretion of $\mathrm{ABO}$ blood group antigens as host susceptibility factor in the spondylarthropathies. BMF 1987;294:208-10.

12 Blackwell CC. Genetic susceptibility to infectious agents. Proceedings of the Roval College of Phvsicians of Edinburgh 1989:19:129-35.

13 Mackenzie JS, Fimmell PJ. The effect of ABO blood groups on the incidence of epidemic influenza and on the response to live attenuated and detergent of epidemic influenza and on the response to live attenuated
split influenza vaccines. Fournal of Hygiene 1978;80:21-30.

14 MCDonald JC, Zuckerman AJ. ABO blood groups and acute respiratorv virus disease. BMF 1962;ii:89-90.

15 Potter CW. Haemagglutination inhibition antibody to various influenza viruses and adenoviruses in individuals of blood groups $\mathrm{A}$ and $\mathrm{O}$. Fournal of Hygiene 1969;67:67-74.

16 Mollison PL. Blood transfusion in clinical medicine. 6th ed. Oxford: Blackwell, 1979:414-82

17 Blackwell CC, Weir DM, James VS, Cartwright KAV, Stuart JM, Jones DM The Stonehouse study: secretor status and carriage of Neisseria meningitidis and Neisseria lactamica. Epidemiol Infect 1989;102:1-10.

18 Mourant AE, Kopeć AC, Domaniewska-Sobczak K. The distribution of the human blood groups and other polymorphisms. London: Oxford University Press, 1976.

19 Burford-Mason AP, Welsby JCP, Willoughby JMT. Oral carriage of Candida albicans, $\mathrm{ABO}$ blood group and secretor status in healthy individuals. J.Met Vet Mycol 1988:26:49-56.

20 Blackwell CC, Aly FZM, James VS, W'eir DM, Collier A, Patrick AW, et al. Blood group, secretor status and oral carriage of yeasts among patients with diabetes mellitus. Diabet Res 1989;12:101-4.

21 Blackwell CC, Weir DM, James VS, Todd WTA, Banatvala N, Chaudhur AKR, et al. Secretor status, smoking and carriage of Neisseria meningitidis. Epidemiol Infect 1990;104:203-9.

22 May SJ, Blackwell CC. W'eir DM. Lewis blood group antigen, a receptor for Candida species. FEMS Microbiol Immunol 1989;47:407-10.

23 Rahat A, Stewart J, Blackwell CC, Weir DM. Semi-quantative determination of $\mathrm{H}$ type 1 and type 2 antigens on buccal epithelial cells and in saliva of secretors and non-secretors. Vox Sang 1990;57:101-5.

(Accepted 17 July 1991

\title{
Mode of delivery after one caesarean section: audit of current practice in a health region
}

\author{
Catherine M Paterson, Nigel J St G Saunders
}

Abstract

Objective-To audit the subsequent obstetric management of women who had had one previous baby delivered by caesarean section.

Design-Retrospective analysis of a regional obstetric database.

Setting-Data derived from the 17 obstetric units in North West Thames region.

Subjects - 1059 women who delivered a singleton fetus of at least 37 weeks' gestation with a cephalic presentation in 1988 who had a history of one previous caesarean section and no other deliveries.

Main outcome measures-Mode of delivery, postnatal morbidity, and duration of hospital stay.

Results-395 (37\%) women were delivered by elective repeat caesarean section and $664(63 \%)$ were allowed a trial of labour. Maternal height and birth weight of the previous infant differed significantly between those who were and those who were not allowed to labour. $471(71 \%)$ of those allowed to labour achieved a vaginal delivery. In individual units there was no significant correlation between the proportion of patients allowed to labour and the rate of the successful trial of labour. There was a trend towards greater success rates in units that allowed a longer duration of labour $(p<0.05)$ and units with greater use of oxytocin for augmentation of labour (not significant). Both elective and intrapartum caesarean section was associated with a significantly higher rate of postnatal infection than vaginal delivery $(14.7 \%$ and $16.0 \% v 3.4 \%)$.

Conclusions-In patients with a history of caesarean section there is no evidence that the likelihood of successful vaginal delivery after trial of labour is modified by the proportion of such patients allowed the option of attempted vaginal delivery. Until selection criteria of adequate prognostic value can be identified a more liberal approach to allowing women a trial of labour seems justified.

\section{Introduction}

The rising incidence of caesarean birth in Britain and elsewhere is a cause for concern both in terms of the associated increase in clinical and social morbidity for the mother and increased cost to the health service. Repeat caesarean section makes a major contribution to the overall rate of caesarean section. One strategy for reducing the rate of caesarean birth, therefore, is to allow women with a history of lower segment caesarean section the option of a trial of labour in their next pregnancy unless there are specific contraindications.

Many studies attest to the safety of a properly conducted trial of labour in women who have previously delivered by caesarean section, and successful vaginal delivery can be expected in around two thirds of such cases. In a comprehensive review Lavin et al concluded that a properly managed trial was associated with an acceptably low incidence of scar dehiscence and perinatal mortality.' Furthermore, no maternal deaths were identified. This is in contrast to the recognised contribution of repeat elective caesarean section to maternal mortality. ${ }^{2}$

Factors known to influence the outcome of a trial of
Correspondence to:

Dr Paterson.

BMf 1991;303:818-21 
labour include the indication for the original caesarean and the stage of labour at which it was performed ${ }^{3}$; a history of previous vaginal delivery ${ }^{4}$; and the presence of fetal macrosomia. ${ }^{5}$ Nevertheless, despite adverse factors such as a history of cephalopelvic disproportion or suspected fetal macrosomia vaginal delivery may still be expected in most cases. These observations have led some to conclude, given the apparent safety of trial of labour and the rather limited ability to predict outcome before labour, that most if not all patients should be offered the option of attempted vaginal delivery. ${ }^{6}$ This philosophy is not universal, and the proportion of women allowed a trial of labour can vary greatly among different obstetric units. Criteria used to select patients for trial of labour at present may be subjective and arbitrary. We analysed a population of potential candidates for a trial of labour and related the eventual method of delivery both to the characteristics of the individual pregnancies and to intraregional differences in obstetric practice.

\section{Patients and methods}

The St Mary's maternity information system is an online obstetric data collection system. It is presently in use in all maternity units managed by the North West Thames Regional Health Authority. These units range from suburban district general hospitals serving rural populations to inner city teaching hospitals. At the end of each year patient identifiers are removed to ensure anonymity and the total dataset is transferred to the University of London Amdahl computer for statistical analysis. In the year ending December 1988

TABLE I-Rates of caesarean section in women with singleton pregnancies in North West Thames Health region in 1988 according to complications or obstetric history

\begin{tabular}{lccc}
\hline & $\begin{array}{c}\text { No (\%) of all } \\
\text { singletons }\end{array}$ & $\begin{array}{c}\text { No (\%) who } \\
\text { had caesarean } \\
\text { section }\end{array}$ & $\begin{array}{c}\text { Percentage of } \\
\text { all caesarean } \\
\text { sections }\end{array}$ \\
\hline $\begin{array}{l}\text { Preterm delivery } \\
\text { Malpresentation }\end{array}$ & $2391(7)$ & $637(27)$ & 15 \\
Primiparas & $1339(4)$ & $879(66)$ & 21 \\
$\begin{array}{l}\text { Multiparas, no previous caesarean section } \\
\text { Multiparas, one previous caesarean section, no vaginal }\end{array}$ & $14722(40)$ & $1391(9)$ & 33 \\
$\begin{array}{l}\text { deliveries } \\
\text { Multiparas, one previous caesarean section, } \geqslant 1 \text { vaginal } \\
\text { delivery }\end{array}$ & $16518(45)$ & $448(3)$ & 11 \\
$\begin{array}{l}\text { Multiparas, }>1 \text { previous caesarean section } \\
\text { Total }\end{array}$ & $435(1)$ & $988(5)$ & 14 \\
\hline
\end{tabular}

$\star$ Presentation at term was not cephalic.

TABLE II-Characteristics of women delivered by elective repeat caesarean section compared with those allowed a trial of labour. Figures are mean $(S D)$ values

\begin{tabular}{|c|c|c|c|}
\hline & $\begin{array}{l}\text { Elective caesarean } \\
\text { section }(\mathbf{n}=395)\end{array}$ & $\begin{array}{l}\text { Trial of labour } \\
\quad(n=664)\end{array}$ & $\begin{array}{l}95 \% \text { Confidence } \\
\text { intervals for } \\
\text { differences in } \\
\text { means or } \\
\text { percentages }\end{array}$ \\
\hline $\begin{array}{l}\text { Maternal age (years) } \\
\text { Maternal height (cm) } \\
\text { Gestational age at delivery (weeks) } \\
\text { Birth weight of previous infant }(\mathrm{g}) \\
\text { Birth weight in current pregnancy }(\mathrm{g})\end{array}$ & $\begin{array}{r}30 \cdot 5(5 \cdot 0) \\
157 \cdot 9(6 \cdot 7) \\
38 \cdot 7(1 \cdot 2) \\
3366(655) \\
3439(549)\end{array}$ & $\begin{array}{r}29 \cdot 0(4 \cdot 8) \\
160 \cdot 7(6 \cdot 6) \\
39 \cdot 5(1 \cdot 2) \\
3085(774) \\
3369(467)\end{array}$ & $\begin{array}{l}0.9 \text { to } 2 \cdot 1 \\
1 \cdot 2 \text { to } 2 \cdot 9 \\
0 \cdot 6 \text { to } 0 \cdot 9 \\
189 \text { to } 373 \\
7 \text { to } 133\end{array}$ \\
\hline
\end{tabular}

TABLE III-Comparison of characteristics and outcomes in women with successful and unsuccessful trials of labour. Figures are mean $(S D)$ values

\begin{tabular}{lcccc}
\hline & \multicolumn{3}{c}{ Trial of labour } & $\begin{array}{c}95 \% \text { Confidence } \\
\text { intervals for } \\
\text { differences in } \\
\text { means or }\end{array}$ \\
\cline { 2 - 5 } & $\begin{array}{c}\text { Elective } \\
\text { caesarean } \\
\text { section } \\
(\mathbf{n}=395)\end{array}$ & $\begin{array}{c}\text { Failed } \\
(\mathbf{n}=193)\end{array}$ & $\begin{array}{c}\text { Successful } \\
(\mathbf{n}=471)\end{array}$ & $\begin{array}{c}\text { percentages for trial } \\
\text { of labour }\end{array}$ \\
\hline Maternal age (years) & $30 \cdot 5(5 \cdot 0)$ & $29 \cdot 2(4 \cdot 8)$ & $28 \cdot 8(4 \cdot 7)$ & $-0 \cdot 4$ to $1 \cdot 2$ \\
Maternal height (cm) & $157 \cdot 9(6 \cdot 7)$ & $157 \cdot 7(6 \cdot 5)$ & $160 \cdot 9(6 \cdot 4)$ & $2 \cdot 1$ to $4 \cdot 2$ \\
Birth weight of previous baby (g) & $3366(655)$ & $3097(737)$ & $3079(796)$ & -144 to 150 \\
Birth weight of current baby (g) & $3439(549)$ & $3421(494)$ & $3348(453)$ & $-5 \cdot 6$ to 152 \\
Postnatal stay (median no of days) & 5 & 5 & 2 & 6.9 to $17 \cdot 8$ \\
Postnatal infection (\%) & $14 \cdot 7$ & $16 \cdot 0$ & $3 \cdot 4$ & 6 \\
\hline
\end{tabular}

data were collected for 36727 singleton births from 17 units, and these form the basis for this study.

In order to study a relatively homogeneous population we confined the analysis to those pregnant women with a singleton fetus of at least 37 weeks' gestation at delivery with cephalic presentation and a history of one previous caesarean section and no other deliveries.

Variables studied included maternal age, height, and body mass index; fetal weight in both the first and current pregnancy; fetal gestation; the presence of abnormal cardiotocograms or meconium staining of the liquor during labour; induction and augmentation of labour; duration of labour; mode of delivery; duration of postnatal stay in hospital; and the presence of postnatal infection. Induction of labour is defined as the initiation of uterine contractions by artificial means (artificial rupture of the membranes or the use of prostaglandins and/or oxytocin, or both). Augmentation refers to the use of oxytocins in spontaneous labour, and the duration of labour is the time between the onset of regular contractions associated with cervical dilatation and delivery of the infant.

The data were analysed to identify, firstly, any differences in maternal and neonatal characteristics between women allowed to labour and those delivered by elective repeat caesarean section; secondly, intraregional differences in outcome in relation to variations in unit practice (for example, the proportion of patients allowed a trial of labour, rates of augmentation with oxytocin, etc); and, thirdly, prognostic markers for successful trial of labour.

The $95 \%$ confidence intervals for differences in mean values and proportions were calculated by using Confidence Interval Analysis software. ${ }^{7}$ Significance for correlation coefficients was calculated by using the statistical package for the social sciences $\mathrm{X}$ (SPSS X). ${ }^{8}$

\section{Results}

Table I shows all the caesarean sections performed in 1988 in North West Thames region (4255) classified into seven mutually exclusive categories. In all, 1516 $(36 \%)$ were complicated by malpresentation or prematurity, and of the remainder (for infants born at term and with a cephalic presentation), $1839(44 \%)$ women had a primary caesarean section, $218(5 \%)$ had had more than one previous caesarean section, and 682 (16\%) had had one previous caesarean section. Of the 1494 women with a singleton birth who had had one previous caesarean section, 1059 (3\% of the singleton obstetric population) had not had a previous vaginal delivery; these women formed the study group. In all, $395(37 \%)$ were delivered by elective repeat caesarean section and $664(63 \%)$ were allowed a trial of labour. The incidence of antenatal complications such as hypertension, diabetes, and antepartum haemorrhage was similar in both groups. Table II gives mean values for maternal age and height, gestational age, and fetal birth weight in the current and previous pregnancies.

In total, $471(71 \%)$ of the 664 patients allowed to proceed to labour achieved a vaginal delivery. Table III compares the characteristics of women with failed and successful trials of labour. Women who achieved a vaginal delivery were significantly taller than those who required an emergency caesarean section.

In individual maternity units a trial of labour was allowed in $35 \%$ to $77 \%$ of women eligible for the study, and the rate of vaginal delivery in these women varied from $47 \%$ to $87 \%$. There was no significant correlation between the proportion of patients allowed to proceed to labour and the rate of successful trial of labour in each unit $(r=-0 \cdot 09$, fig 1$)$. There was a trend towards a greater success rate in those units allowing their patients a longer labour $(r=0.51, p<0 \cdot 05$, fig 2$)$. There 


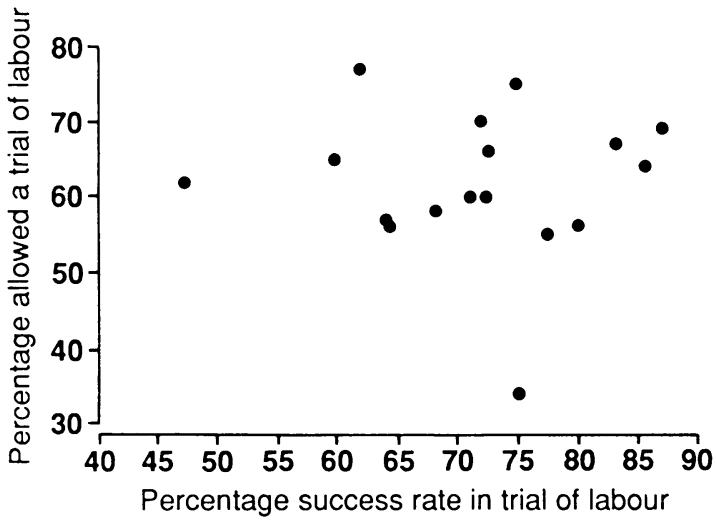

FIG 1-Percentage of women allowed trial of labour in each of 17 units plotted against their vaginal delivery rate

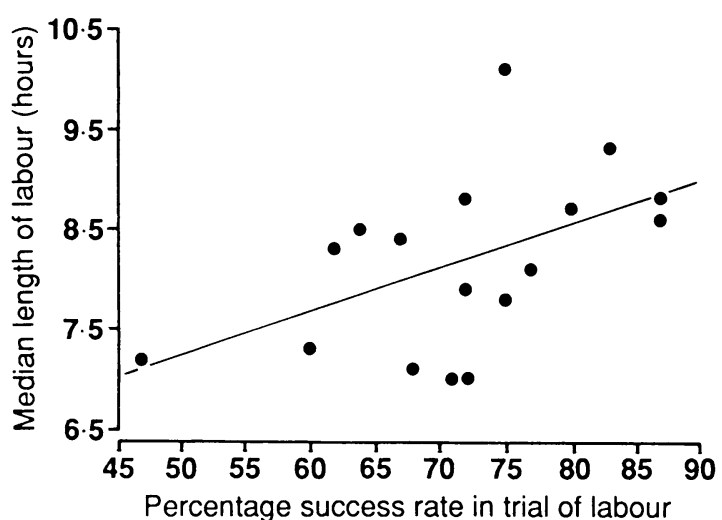

FIG 2-Median duration of labour in women with a successful trial of labour for each unit plotted against vaginal delivery rate of women allowed a trial of labour

was also a non-significant trend towards higher rates of vaginal delivery in those units where there was a greater use of oxytocin for augmentation of labour $(r=0.31$ ) (augmentation rates ranged from $0 \%$ to $40 \%$ and vaginal delivery rates from $33 \%$ to $87 \%$ ).

The vaginal delivery rates in spontaneous and induced labours were similar $(70 \cdot 6 \%$ and $74 \cdot 4 \%$ respectively), as were the rates in augmented and nonaugmented labours $(73 \%$ and $70 \%$ respectively). The rate of vaginal delivery was not influenced by the presence of meconium staining of the liquor or abnormalities in fetal heart rate.

When compared with vaginal delivery both elective and intrapartum caesarean sections were associated with significantly higher rates of postnatal infection and an increased postnatal hospital stay (table III).

There were no maternal deaths associated with a trial of labour. One neonatal death occurred owing to birth asphyxia after emergency caesarean section performed for fetal distress in labour. At operation there was no evidence of scar dehiscence.

\section{Discussion}

The decision to allow a patient a trial of labour after a previous caesarean section is influenced by a complex interplay of factors including obstetric history, patients' wishes, and obstetricians' perception of the risks of labour and the likelihood of success in any particular case. A computer database such as the St Mary's maternity information system will therefore not contain information on all the factors likely to affect obstetric decision making and clinical outcome. The strength of the system lies in the on line collection of data on all women delivered within the same year in the same geographical region. This allowed us to select a homogeneous subset of patients allowed a trial of labour for study while maintaining a sample popula- tion of over 1000 cases. We were also able to compare the outcome of such pregnancies in relation to variations in unit practice.

In our study $70 \%$ of patients allowed a trial of labour achieved a vaginal delivery, which is similar to the figure of $66 \cdot 7 \%$ quoted by Lavin $e t$ al in a review article ${ }^{1}$ but less than the figure of $90 \%$ quoted by Molloy $e t a l$, who included in their study all women regardless of whether they had had a previous vaginal delivery. ${ }^{9}$

The maternal height and the birth weight of the previous infant differed significantly between those women delivered by elective repeat section and those allowed a trial of labour. This suggests that obstetricians are to some extent using these two criteria in formulating their decisions about mode of delivery. This is especially interesting as although the mean birth weight of the previous child was about $300 \mathrm{~g}$ heavier in the group delivered electively, in the current pregnancy the difference in mean birth weight between groups differed by only $70 \mathrm{~g}$. It follows, therefore, that birth weight in the previous pregnancy perhaps should not exert undue influence on subsequent management decisions.

When the outcome of trial of labour was analysed in relation to variations in obstetric management in the 17 hospitals contributing to the database several points emerged. It has been suggested that success rates in cases of trial of labour may be influenced by the degree of prior selection, ${ }^{3}$ with high success rates to be expected when only patients with the most favourable prognostic features are allowed to proceed to labour. This relation was not apparent within our region. Eleven units achieved vaginal delivery rates greater than $70 \%$ in women allowed a trial of labour; seven of these had an elective caesarean section rate of less than $40 \%$ and two of less than $30 \%$ (fig 1 ). The decision to perform an elective caesarean section may, of course, have been influenced by factors of which we had no knowledge, but by selecting a relatively homogeneous low risk population - that is, women carrying mature singleton infants with a cephalic presentationthe impact of such extraneous factors should be minimised.

A trend towards higher vaginal delivery rates was observed in the units where oxytocin augmentation of labour was practised more commonly and where a longer labour was allowed. Good results have been reported with oxytocin induction or augmentation of labour, ${ }^{6}{ }^{10}$ and the results presented here support the view that oxytocin augmentation should be considered in women with dysfunctional labour rather than early recourse to caesarean section.

Women who achieve vaginal delivery are spared the morbidity and prolonged convalescence associated with caesarean section and are much less likely to require abdominal delivery in future pregnancies. At present objective criteria with which to predict accurately the outcome of a trial of labour are lacking, and our regional data do not support the hypothesis that units with a selective approach to trial of labour achieve higher rates of trial of labour than those practising a more liberal policy. This observation may help to engender a more positive approach towards trials of labour, with more women requesting, or being offered, this option as a result.

One of the advantages of the continuous routine collection of data in the North West Thames Health region is that it will be possible to monitor the effect of feedback of analyses such as these, and we plan to do a similar study of practice in 1993.

We thank Professor Beard, who initiated the data collection system, for his advice; Andy Dawson and the maternity team at the regional computer centre; the consultants in participating hospitals; and the midwives who enter the data. 
1 Lavin JP, Stephens RJ, Miodovnik M, Barden TP. Vaginal delivery in patients with a prior cesarean section. Obstet Gynecol 1982;59:135-48.

Evrard JR Gold EM. Cesan section and maternal mortality in Rhode Island. Incidence and risk factors, 1965-1975. Obstet Gynecol 1977;50: Island.

3 Duff $\mathrm{P}$, Southmayd $\mathrm{K}$, Read JA. Outcome of trial of labor in patients with a single low transverse caesarean for dystocia. Obstet Gynecol 1988;71:

4 Whiteside DC, Mahan CS, Cook JC. Factors associated with successful vaginal delivery after cesarean section. $\mathcal{F}$ Reprod Med 1983;28:785-8.

5 Flamm BL, Goings JR. Vaginal birth after cesarean section: is suspected fetal macrosomia a contraindication? Obstet Gynecol 1989;74:694-7.
6 Phelan JP, Clark SL, Diaz F, Paul RH. Vaginal birth after cesarean. Amf Obstet Gynecol 1987;157:1510-5.

Gardner MJ, Gardner SB, Winter PD. Confidence Interval Analysis (CIA) microcomputer program manual. London: BMJ, 1989.

Statistical package for the social sciences $X$. User's guide, 2nd ed. New York: McGraw-Hill, 1986.

9 Molloy BG, Sheil O, Duignan NM. Delivery after caesarean section: review of 2176 consecutive cases. BMF 1987;294:1645-7.

10 Meehan FP, Burke G. Trial of labour following prior section; a 5 year prospective study (1982-1987). Eur J Obstet Gynaecol 1988;31:109-17.

(Accepted 17 fuly 1991 )

\title{
Differential effects of enalapril and atenolol on proteinuria and renal haemodynamics in non-diabetic renal disease
}

\author{
Alfred J Apperloo, Dick de Zeeuw, Henk E Sluiter, Paul E de Jong
}

\begin{abstract}
Objective-To compare the antihypertensive, renal haemodynamic and antiproteinuric effect of enalapril and atenolol in patients with proteinuria of non-diabetic origin.
\end{abstract}

Design-Prospective, double blind, randomised 16 week study after a pretreatment period of at least three weeks.

Setting-Outpatient nephrology and hypertension unit.

Patients -27 patients with proteinuria $(>300 \mathrm{mg}$ protein/day) of non-diabetic origin, moderately impaired renal function (creatinine clearance $30-90 \mathrm{ml} / \mathrm{min}$ ), and a pretreatment diastolic blood pressure of $>80 \mathrm{~mm} \mathrm{Hg}$.

Interventions-Treatment with enalapril $(10 \mathrm{mg} /$ day, adjusted between 5 and $40 \mathrm{mg}$, if necessary) or atenolol ( $50 \mathrm{mg} /$ day, adjusted between 25 and $100 \mathrm{mg}$ if necessary) titrated against a target fall in diastolic blood pressure to $<95 \mathrm{~mm} \mathrm{Hg}$ or of $>10 \mathrm{~mm} \mathrm{Hg}$, or both.

Main outcome measures-Blood pressure, renal haemodynamics, and urinary protein excretion.

Results-No differences were detected between the two groups before treatment. The falls in systolic and diastolic blood pressures during treatment were not significantly different between both groups. Proteinuria fell slightly with atenolol but significantly more with enalapril (mean change - 0.38 (95\% confidence interval -0.78 to 0.03$) v-1.2(-1.70$ to $-0.69) \mathrm{g} /$ day respectively, $\mathrm{p}<0.02)$ as did filtration fraction (mean change $-1.8(-2.9$ to -0.7$) v-3.8$ $(-4.9$ to $-2 \cdot 8) \%$ respectively. Serum potassium concentration increased with enalapril (mean change 0.63 (SD 0.51) v 0.19 (0.47) $\mathrm{mmol} / \mathrm{l}, \mathrm{p}<0.05)$.

Conclusions-Enalapril lowers proteinuria more than atenolol in patients with non-diabetic renal disease despite a similar blood pressure lowering effect of both drugs, and its antiproteinuric effect seems to be associated with the characteristic renal haemodynamic effect of angiotensin converting enzyme inhibitors. 9713 EZ Groningen, The Netherlands

Alfred J Apperloo, MD registrar in medicine Dick de Zeeuw, MD, lecturer in nephrology

Henk E Sluiter, $\mathrm{MD}$, registrar in nephrology

Paul E de Jong, MD, head of nephrology unit

Correspondence to: Dr Apperloo.

BMF 1991;303:821-4 are indeed superior to other antihypertensive treatment regimens in this respect remains to be proved. One of the key questions is whether the alleged antiproteinuric (or protective) effect of angiotensin converting enzyme inhibitors is caused by the lowering of systemic blood pressure itself or whether it results from a specific action on renal function. The few studies that have addressed this question in diabetic $c^{4-6}$ and non-diabetic ${ }^{10-11}$ renal disease generally indicated that angiotensin converting enzyme inhibitors are more effective in lowering proteinuria compared with conventional antihypertensive drugs. However, these studies had an open design. More importantly, many studies failed to obtain a similar blood pressure response with the drugs compared. In fact, angiotensin converting enzyme inhibitors seemed to induce a greater fall in blood pressure than the control drugs, leaving open the option that systemic blood pressure effects and not renal effects are the main mechanism by which angiotensin converting enzyme inhibitors reduce proteinuria.

To avoid this possible bias we studied the antiproteinuric and renal haemodynamic effects of the angiotensin converting enzyme inhibitor enalapril compared with the $\beta_{1}$ selective blocker atenolol in a randomised double blind design in 27 patients with proteinuria and non-diabetic renal disease.

\section{Patients and methods}

From a group of patients currently under study in a long term trial of the effects of antihypertensive treatment on the progression of loss of renal function in non-diabetic renal disease we selected the patients with proteinuria of more than $300 \mathrm{mg}$ a day, measured on three consecutive visits in the pretreatment period $(n=27)$. Other entry criteria were a creatinine clearance of $30-90 \mathrm{ml} / \mathrm{min}$, a diastolic blood pressure $>80 \mathrm{~mm} \mathrm{Hg}$, and no contraindications for treatment with a $\beta$ blocker or an angiotensin converting enzyme inhibitor. The cause of the renal disease in these 27 patients (five women, 22 men; mean (SD) age 49 (13) years) was chronic glomerulonephritis (13 patients), chronic interstitial nephritis or pyelonephritis (seven), and nephrosclerosis (seven). The study was approved by the local medical ethics committee. Informed consent was obtained from each patient.

All patients adhered to a sodium restricted diet (50-80 $\mathrm{mmol}$ sodium/day). Protein intake was $0 \cdot 8-1.0 \mathrm{~g} / \mathrm{kg}$ body weight in the patients with a creatinine clearance of $60-90 \mathrm{ml} / \mathrm{min}$ and $0 \cdot 6-0 \cdot 8 \mathrm{~g} / \mathrm{kg}$ body weight in those with a creatinine clearance of $30-60 \mathrm{ml} / \mathrm{min}$. All antihypertensive drugs were withdrawn at least three weeks before active treatment started. In the pretreatment period the patients were 